\title{
Results of a nation-wide retrospective study of lymphadenectomy for esophagogastric junction carcinoma
}

\author{
Hiroharu Yamashita ${ }^{1}$ - Yasuyuki Seto ${ }^{1} \cdot$ Takeshi Sano $^{2} \cdot$ Hiroyasu Makuuchi $^{3} \cdot$ \\ Nobutoshi Ando ${ }^{4} \cdot$ Mitsuru Sasako $^{5}$. On behalf of the Japanese Gastric Cancer \\ Association and the Japan Esophageal Society
}

Received: 5 September 2016/ Accepted: 15 October 2016/Published online: 28 October 2016

(c) The International Gastric Cancer Association and The Japanese Gastric Cancer Association 2016

\begin{abstract}
Background Esophagogastric junction (EGJ) carcinoma has attracted considerable attention because of the marked increase in its incidence globally. However, the optimal extent of esophagogastric resection for this tumor entity remains highly controversial.

Methods This was a questionnaire-based national retrospective study undertaken in an attempt to define the optimal extent of lymph node dissection for EGJ cancer. Data from patients with EGJ carcinoma, less than $40 \mathrm{~mm}$ in diameter, who underwent R0 resection between January 2001 and December 2010 were reviewed.

Results Clinical records of 2807 patients without preoperative therapy were included in the analysis. There are distinct disparities in terms of the nodal dissection rate according to histology and the predominant tumor location. Nodal metastases frequently involved the abdominal nodes, especially those at the right and left cardia, lesser curvature and along the left gastric artery. Nodes along the distal portion of the
\end{abstract}

Hiroharu Yamashita

hyamashi-tky@umin.net

1 Department of Gastrointestinal Surgery, Graduate School of Medicine, The University of Tokyo, 7-3-1, Hongo, Bunkyoku, Tokyo 113-8655, Japan

2 Department of Gastroenterological Surgery, Cancer Institute Hospital, 3-8-31, Ariake, Koto-ku, Tokyo 135-8550, Japan

3 Department of Surgery, Tokai University School of Medicine, Isehara, Kanagawa 259-1193, Japan

4 International Goodwill Hospital, Yokohama, Kanagawa 245-0006, Japan

5 Department of Multidisciplinary Surgical Oncology, Hyogo College of Medicine, 1-1, Mukogawacho, Nishinomiya, Hyogo 663-8501, Japan stomach were much less often metastatic, and their dissection seemed unlikely to be beneficial. Lower mediastinal node dissection might contribute to improving survival for patients with esophagus-predominant EGJ cancer. However, due to low dissection rates for nodes of the middle and upper mediastinum, no conclusive result was obtained regarding the optimal extent of nodal dissection in this region.

Conclusions Complete nodal clearance along the distal portion of the stomach offers marginal survival benefits for patients with EGJ cancers less than $4 \mathrm{~cm}$ in diameter. The optimal extent of esophageal resection and the benefits of mediastinal node dissection remain issues to be addressed in managing patients with esophagus-predominant EGJ cancers.

Keywords Esophagogastric junction - Adenocarcinoma . Squamous cell carcinoma - Proximal gastrectomy

\section{Introduction}

The incidence of esophageal adenocarcinoma is rising dramatically worldwide [1, 2]. These tumors are located mainly at the distal esophagus and/or esophagogastric junction (EGJ) in Western countries and are widely believed to be associated with increased body weight, gastroesophageal reflux disease and premalignant Barrett epithelium. In contrast, the histology of esophageal cancer is squamous cell carcinoma (SCC) in the vast majority of cases in Japan, and the incidence of esophageal adenocarcinoma remains very low [3], while gastric cancer mortality is still high mainly because of the higher prevalence of Helicobacter pylori infection than seen in Western countries [4]. Meanwhile, the number of patients with EGJ carcinoma has been increasing over the past 4 decades. The proportion of this carcinoma among all gastric carcinomas 
has shown a four-fold increase, according to the data from a single high-volume cancer center in Japan [5]. Interestingly, Siewert type I carcinoma, which is basically consistent with distal esophageal adenocarcinoma, constituted a minority of cases during this period, while Siewert type II, carcinoma of the true cardia, accounts for a growing fraction of EGJ carcinoma cases in Japan [5].

It is generally acknowledged that Siewert type I and type III carcinomas are to be treated as esophageal and gastric tumors, respectively [6]. There is considerable controversy, however, as to whether Siewert type II carcinoma is actually esophageal or gastric cancer. Subsequently, the optimal surgical procedure for Siewert type II tumors has yet to be established. Subtotal esophagectomy via right thoracotomy and laparotomy, transhiatal subtotal esophagectomy via laparotomy with cervical anastomosis and extended total gastrectomy via laparotomy alone are all feasible and have achieved similar outcomes [6]. These three procedures are extremely different in terms of surgical approach, type of reconstruction and, more importantly, the extent of gastric and esophageal resection. Therefore, mortality, morbidity and the patient's quality of life (QOL) after surgery are not deemed equivalent. Clearly, the surgical approach should be selected with the ultimate aim of achieving residual tumor elimination. Therefore, the optimal treatment strategy for a Siewert type II tumor would presumably depend on the extent of esophageal and gastric involvement by the tumor as well as the pattern of any associated lymphatic spread.

In Japan, a tumor is designated an EGJ carcinoma according to the current Japanese classification system, regardless of histological type, when its epicenter is located within $2 \mathrm{~cm}$ proximal or distal to the EGJ [7]. Another issue to be addressed is the difference of lymphatic involvement between adenocarcinoma and squamous carcinoma. Although it should be the same theoretically if they are located in the same area of the organs, the treatment strategy for locoregional esophageal cancer is to initially classify the tumor into either SCC or adenocarcinoma (AC), according to the NCCN Clinical Practice Guidelines in Oncology [8].

We conducted a nationwide survey to characterize the lymph node spread pattern of EGJ carcinoma in a large cohort, aiming mainly to evaluate the optimal extent of lymph node dissection according to both the predominant location and the histology of tumors.

\section{Patients and methods}

\section{Nationwide questionnaire surveillance of EGJ carcinoma}

This national questionnaire survey included patients with EGJ carcinoma who had undergone R0 resection between January 2001 and December 2010. EGJ carcinoma in this survey was defined as having its epicenter within $2 \mathrm{~cm}$ proximal or $2 \mathrm{~cm}$ distal to the anatomical EGJ, according to the definition promulgated by the Japanese Gastric Cancer Association [7] and the Japan Esophageal Society [9]. We selected tumors of $40 \mathrm{~mm}$ or less in dimension since large tumors were apparently associated with poor macroscopic recognition of the anatomical EGJ. Tumor histology was classified into five subtypes: SCC, differentiated AC, undifferentiated AC, adenosquamous carcinoma and other type. Pre- and postoperative treatments were defined as chemotherapy, radiation, chemoradiation, no therapy or unknown; chemotherapeutic regimens and radiation doses were not specified. Tumor depth was pathologically classified into four groups as pT1a, tumor confined to the mucosa; T1b, tumor confined to the submucosa; $\mathrm{T} 2$, tumor invasion of the muscularis propria but not deeper layers; T3/T4, tumor invasion beyond the muscularis propria. T3 and T4 were classified as one category since the definitions of $\mathrm{T} 3$ and $\mathrm{T} 4$ provided by the Japanese Gastric Cancer Association and the Japan Esophageal Society were not entirely consistent. Lymph node station numbers were determined according to the uniform definition established by the Japanese Gastric Cancer Association and the Japan Esophageal Society.

The International Union Against Cancer (UICC) TNM staging system for EGJ cancer was used for nodal staging [10]: pN0: no metastasis; pN1: 1-2 positive lymph nodes; pN2: 3-6 positive nodes; $\mathrm{pN} 3$ : 7 or more positive nodes. Surgical procedures were not included among the questionnaire items, while the numbers of metastatic and dissected nodes at each nodal station and the thoroughness of nodal dissection (complete, incomplete or not dissected) had to be provided. Nodal dissection was regarded as "not dissected" at a station wherein the number of dissected or metastatic nodes was not described.

Lymph node recurrence sites were sub-classified into cervical, upper mediastinal, middle mediastinal, lower mediastinal, celiac, abdominal para-aortic, porta hepatis, other and undefined. Carcinoma in this study was subclassified, according to the epicenter of the tumor and the dominant area of tumor involvement, into five groups using the symbols E (esophageal) and G (gastric) with the dominant area of invasion described first, i.e., $\mathrm{E}, \mathrm{EG}, \mathrm{E}=\mathrm{G}$ (the two areas equally involved), GE or $G$ [7]. In this Japanese classification, tumors without invasion to neighboring organs are also included if the epicenter is located within $2 \mathrm{~cm}$ proximal or distal to the EGJ. Our protocol was approved by the ethics committee of the Faculty of Medicine at the University of Tokyo. 


\section{Statistical analysis}

All statistical calculations were carried out using JMP Pro 12.2.0 (SAS Institute, Cary, NC, USA). The overall survival (OS) and recurrence-free survival (RFS) rates were calculated from the operation date to death of any cause and to recurrence or death of any cause that came earlier, respectively. OS and RFS were evaluated by Kaplan-Meier curves, and the log-rank test was used for comparisons. Data from patients who were alive without recurrence at the last follow-up were censored for the RFS analysis. The data-accrual period was August 2012 through May 2013. P values less than 0.05 were considered to indicate a statistically significant difference in all analyses.

We used the same method as described previously [11] to evaluate the therapeutic benefits of lymph node dissection. In brief, the frequency of metastasis to each station was determined by dividing the number of patients with metastasis at that station by the number of patients in whom that station was dissected. The cumulative 5-year OS rate of patients with metastasis at each nodal station was calculated, without taking the presence/absence of metastasis at other nodal stations into account. An index of the benefit gained by dissection at each station was calculated by multiplying the frequency of metastasis at that station by the 5-year OS rate of patients with metastasis at that station. The index was not determined for stations that had not been dissected in all patients or in which no metastasis was reported in any of those in whom the station had been dissected. Likewise, we did not determine the index when all surviving patients with metastasis at the station had been censored within a 5 -year period.

\section{Results}

\section{Characteristics of the patients}

Among 660 total member hospitals of the Japanese Gastric Cancer Association and/or the Japan Esophageal Society, 273 institutions $(41.4 \%)$ participated in this study, providing data from 3175 patients who fulfilled the registration criteria. The annual number of operative cases has increased steadily since 2001, especially for AC (Fig. 1).

Fifty-one patients had a prior history of gastrectomy. Preoperative chemotherapy, chemoradiation and radiation therapy were employed in 235, 42 and 2 subjects, respectively. Therapy prior to surgery was not described in two subjects. Total number of dissected and/or metastatic lymph nodes was unknown in 36 patients. The remaining 2807 patients without prior gastrectomy or preoperative therapy were included in the following analysis. Tumor histology was differentiated adenocarcinoma in 1926 $(68.6 \%)$, undifferentiated adenocarcinoma in 458 (16.3\%), SCC in $370(13.2 \%)$, adenosquamous carcinoma in 16 $(0.6 \%)$ and other type in 37 patients. The median follow-up duration of 2114 surviving patients was 4.5 years (interquartile range: 2.7-6.2). Demographic features of these
Fig. 1 Changing trend in the number of surgeries for esophagogastric junction carcinoma during the 2001-2010 period

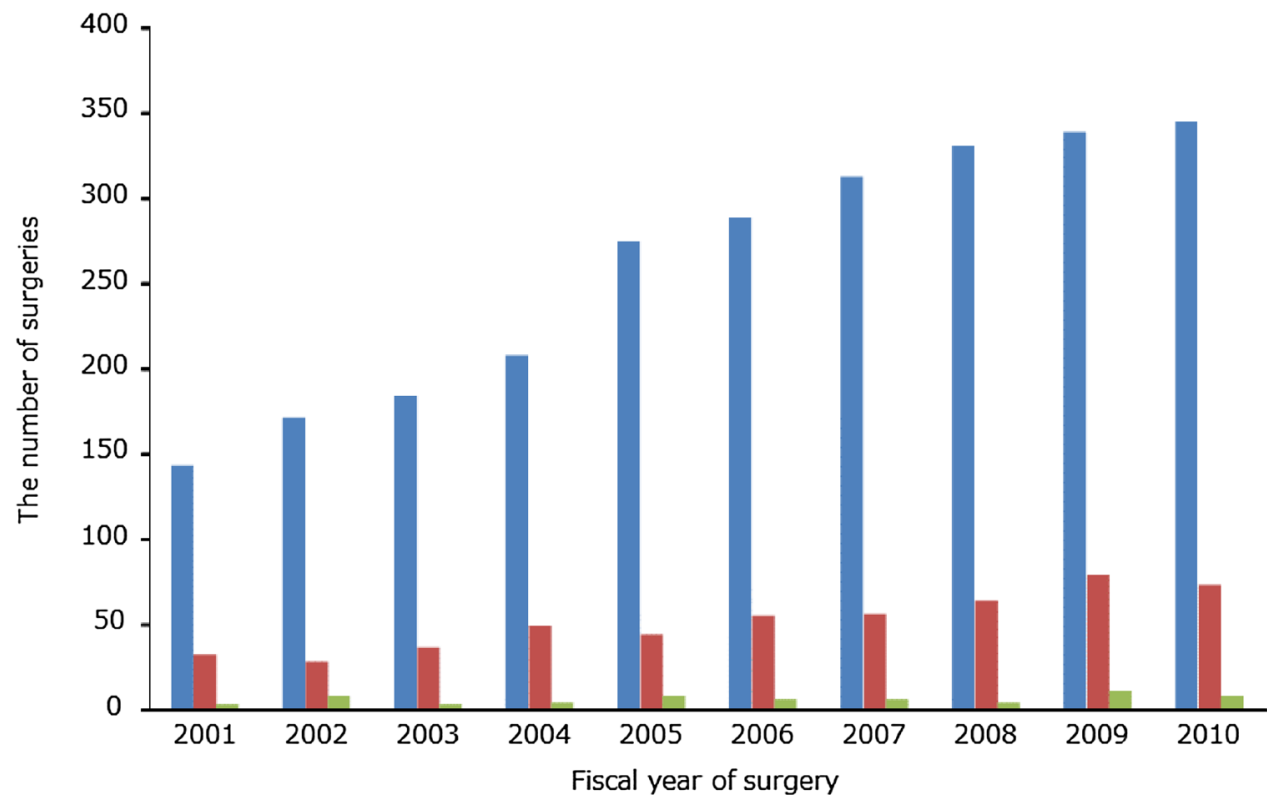

$\begin{array}{lcccccccccc}\square \text { AC } & 143 & 171 & 184 & 208 & 275 & 289 & 313 & 331 & 339 & 345 \\ \square \text { SCC } & 32 & 28 & 36 & 49 & 44 & 55 & 56 & 64 & 79 & 73 \\ \square \text { Other } & 3 & 8 & 3 & 4 & 8 & 6 & 6 & 4 & 11 & 8\end{array}$


2807 patients are presented, according to tumor histology, in Table 1. Mean age was 67.1 years, and most of the patient population was male (male:female, 4:1). Adjuvant postoperative therapy was not given to 2222 (79.2\%) patients. The tumor epicenters were mainly at the gastric side (GE, G) in AC (73.4\%) and at the esophageal side (E, $\mathrm{EG}, \mathrm{E}=\mathrm{G})$ in $\mathrm{SCC}(88.4 \%)$ cases.

\section{Rate of dissection according to the tumor epicenter}

Pathological T classification of 989 esophagus-predominant EGJ cancers was T1a in 141, T1b in 421, T2 in 166 and T3/4 in 261 patients. Perigastric nodes (nos. 1, 2, 3, 7) were constantly dissected, followed by lower mediastinal (nos. 110, 111), suprapancreatic (nos. 8a, 9, 11p) and other perigastric (nos. 4sa, 4sb) nodes (Fig. 2a) in incidence of dissection. Dissection of other lymph node areas appeared to be performed on a highly selective basis, since the frequency of dissection for the cervical, upper mediastinal and middle mediastinal nodes, except no. 108, as well as the nodes along the distal portion of the stomach (nos. $4 \mathrm{~d}, 5$, 6), was less than $40 \%$ even in patients with T3/4 tumors. In marked contrast, the frequency of nodal dissection in the mediastinum and parahiatal area was very low for tumors located predominantly in the stomach, regardless of their histology (Fig. 2b).

In light of the possible difference between AC and SCC, esophagus-predominant tumors were thereafter subdivided according to these two histological subtypes. There was a marked disparity between AC and SCC in terms of the extent of nodal dissection, even for identical tumor locations. Upper and middle mediastinal nodes were preferentially dissected in SCC (Fig. 2c), while dissection rates for these nodes remained below $20 \%$, except for no. 108, in AC (Fig. 2d). Another striking difference was the changing trend in dissection rates of node nos. 4d, 5 and 6 according to tumor depth. Dissection rates for these nodes were increased in $\mathrm{T} 2$ and $\mathrm{T} 3 / 4$ for $\mathrm{AC}$, while not differing remarkably for SCC.

\section{Rate of lymph node metastasis according to the tumor epicenter}

Rates of metastasis rose as the pT stage increased, and this was true for all stations where metastatic nodes were found. Rates of metastasis were very high in node nos. 1, 2, 3 and 7 and moderate in nos. 8a, 9, 11p and 110 in esophaguspredominant cancer (Fig. 3a). Rates were low, but not negligible, at mediastinal nodal stations (nos. 106r, 108, 109,111 ) in T3/4 cancer as reflected by the modest dissection rates for these stations. On the contrary, rates of metastasis were extremely low in all mediastinal stations examined in stomach-predominant cancer, and this was reflected by their low dissection rates (Fig. 3b). Rates of metastasis at node nos. $4 \mathrm{sa}, 4 \mathrm{sb}, 4 \mathrm{~d}, 5$ and 6 were very low and unrelated to tumor location or pT stage, despite their high dissection rates especially in stomach-predominant cancer cases.

\section{Overall and relapse-free survival rates}

The following analysis was carried out only on AC and SCC patients to focus on the possible difference between these two histological subtypes. Among 2384 patients with AC and 370 with SCC, 469 and 85, respectively, died during follow-up. The cause of death was recurrence in 238 and 57, other in 214 and 26 and unknown in 17 and 2, respectively. Survival curves of patients with AC and those with SCC according to $\mathrm{pT}$ and $\mathrm{pN}$ stage are presented in Fig. 4a-h, respectively. The 5-year OS rate was clearly demarcated according to the pT stage in AC: $90.9 \%$ for $\mathrm{T} 1 \mathrm{a}, 85.9 \%$ for $\mathrm{T} 1 \mathrm{~b}, 78.2 \%$ for $\mathrm{T} 2$ and $52.3 \%$, showing a modest but clear decline, for T3/4 patients. The survival differences between the subgroups were strongly related to the $\mathrm{pN}$ stages; the 5-year OS rate was $86.5 \%$ for pN0 disease, dropping significantly to $69.5 \%$ for $\mathrm{pN} 1$. OS decreased further, to $51.9 \%$, for $\mathrm{pN} 2$ disease, and the survival rate was extremely poor, just $23.6 \%$, for those with $\mathrm{pN} 3$ disease. With $\mathrm{pN} 3$ disease especially, the 5-year RFS rate was $19.6 \%$, and the median RFS of 111 patients was 12.3 months. The 5-year OS rates were $92.8 \%$ for T1a, $86.9 \%$ for $\mathrm{T} 1 \mathrm{~b}, 76.2 \%$ for $\mathrm{T} 2$ and $66.4 \%$ for $\mathrm{T} 3 / 4$ patients among those with SCC, essentially equivalent to the rates in $\mathrm{AC}$ patients. The 5-year OS and RFS rates were similarly distinguishable in SCC cases, though the differences were less dramatic, according to the $\mathrm{pN}$ stage.

\section{Estimated survival benefit by nodal dissection}

Table 2 shows the number of patients with metastatic nodes, the 5-year OS rate for involvement at each nodal station and the calculated index for estimated survival benefit according to pT stage (T1 and T2/3/4). In esophagus-predominant AC, the index was high for node nos. 3, 1 , 2 and 7, in decreasing order. The index values for these stations were also high in esophagus-predominant SCC and stomach-dominant cancer. For T1 tumors, the frequency of nodal metastasis was low except at these stations. In advanced esophagus-predominant AC (T2/3/4), the index values were moderate for node nos. $9,11 \mathrm{p}, 11 \mathrm{~d}$ and 110 . That for node no. 107 was apparently equivalent, though the dissection rate for the middle mediastinal nodes was much lower than that for node nos. 9,11p, 11d and 110. In contrast, the dissection rates for the upper and middle mediastinal nodes were much higher in advanced 
Table 1 Characteristics of 2843 patients with EGJ carcinoma according to tumor histology

\begin{tabular}{|c|c|c|c|c|c|c|}
\hline $\mathrm{AC}$ & & SCC & & Other & & Total \\
\hline$n=2384$ & $(\%)$ & $n=370$ & $(\%)$ & $n=53$ & $(\%)$ & $n=2807$ \\
\hline
\end{tabular}

Age (years)

Median (range)

Average (SD)

Sex

Male

Female

Adjuvant postoperative therapy

None

Chemotherapy

Chemoradiation

Radiation

Unknown

Epicenter of the tumor

Esophagus or EGJ (E, EG, E = G)

Stomach (GE, G)

68 (18-93)

Epicenter (Siewert classification)

I

II

II (no EGJ involvement)

Undefined

Dissected nodes

Median (25-75\% quartile)

Tumor size (mm)

$$
\begin{aligned}
& \leq 10 \\
& \leq 20 \\
& \leq 30 \\
& \leq 40
\end{aligned}
$$

Tumor depth

pT1a

pT1b

pT2

$\mathrm{pT} 3 / 4$

$\mathrm{pN}$ classification

pNO

$\mathrm{pN} 1$

$\mathrm{pN} 2$

$\mathrm{pN} 3$

Lymphovasucular invasion

Negative

Positive

Unknown
$67.2(10.6)$

1931

453

1914

376

6

0

88

634

1750

67 (31-85)

$66.9(9.2)$

$81.0 \quad 278$

$19.0 \quad 92$

$80.3 \quad 263$

$15.8 \quad 88$

$0.3 \quad 5$

$0 \quad 2$

$3.7 \quad 12$

$26.6 \quad 327$

$73.4 \quad 43$

86

1474

820

4

$25(15-38)$

$3.6 \quad 166$

$61.8 \quad 186$

$34.4 \quad 9$

0.29

29 (20-45)

$6.5 \quad 11$

$27.3 \quad 77$

$33.9 \quad 111$

$32.3 \quad 171$

808
769

354

1046

461

523

1708

363

202

111

964

1393

27

$14.8 \quad 49$

$43.9 \quad 116$

$19.3 \quad 61$

$21.9 \quad 144$

$71.6 \quad 208$

15.293

$8.5 \quad 48$

$4.7 \quad 21$

$40.4 \quad 120$

$58.4 \quad 245$

1.15
$69(40-85)$

67.5 (9.9)

68 (18-93)

$67.1(10.4)$

$\begin{array}{lll}77.4 & 2250 & 80.2\end{array}$

$22.6 \quad 557$

19.8

$24.9 \quad 12$

$71.1 \quad 45$

$23.8 \quad 6$

$1.4 \quad 1$

0.50

$3.2 \quad 1$

$88.4 \quad 28$

$11.6 \quad 25$

$44.9 \quad 7$

$50.3 \quad 31$

$2.4 \quad 15$

2.40

$28(14-43)$

$84.9 \quad 2222$

79.2

$11.3 \quad 470$

$1.9 \quad 12$

$0 \quad 2$

$1.9 \quad 101$

$52.8 \quad 989$

$47.1 \quad 1818$

35.2

64.8

$\begin{array}{llr}13.2 & 259 & 9.2\end{array}$

$\begin{array}{lll}58.5 & 1691 & 60.2\end{array}$

$\begin{array}{lll}28.3 & 844 & 30.1\end{array}$

$\begin{array}{lll}0 & 13 & 0.5\end{array}$

$25(16-39)$

$3.8 \quad 169$

6.0

$3.0 \quad 2$

$20.8 \quad 13$

$30.0 \quad 20$

$46.2 \quad 18$

$24.5 \quad 741$

$37.7 \quad 939$

26.4

33.5

34.1

$13.2 \quad 5$

31.420

$16.5 \quad 18$

$38.9 \quad 10$

$34.0 \quad 958$

14.5

$56.2 \quad 35$

$25.1 \quad 14$

$13.0 \quad 2$

$5.7 \quad 2$

$9.4 \quad 408$

42.1

$37.7 \quad 1182$

19.2

$34.0 \quad 540$

24.1

$8.9 \quad 677$

69.5

$66.0 \quad 1951$

16.7

$26.4 \quad 470$

9.0

$3.8 \quad 252$

4.8 $\begin{array}{rl}32.4 & 18 \\ 66.2 & 35 \\ 1.4 & 0\end{array}$

$34.0 \quad 1102$

39.3

$\begin{array}{lll}66.0 & 1673 & 59.6\end{array}$

$0 \quad 32$ esophagus-predominant SCC, and the index values for node nos. 101, 104, 106r and 109 were comparable to those for node nos. 110, 8a, 9 and 11p. The number of tumors with the epicenter in the stomach was 43 in SCC and 1750 in AC. The frequencies of metastasis were relatively high in node nos. $8 \mathrm{a}, 9$ and $11 \mathrm{p}$, while the index values for node nos. $8 \mathrm{a}$ and 9 were low despite the optimal cutoff value for this index not having been clearly determined. 
Fig. 2 Rates of lymph node dissection according to the $\mathrm{pT}$ stage in esophagus-predominant cancer (a), stomachpredominant cancer (b), esophagus-predominant squamous cell carcinoma (c) and esophagus-predominant adenocarcinoma (d)

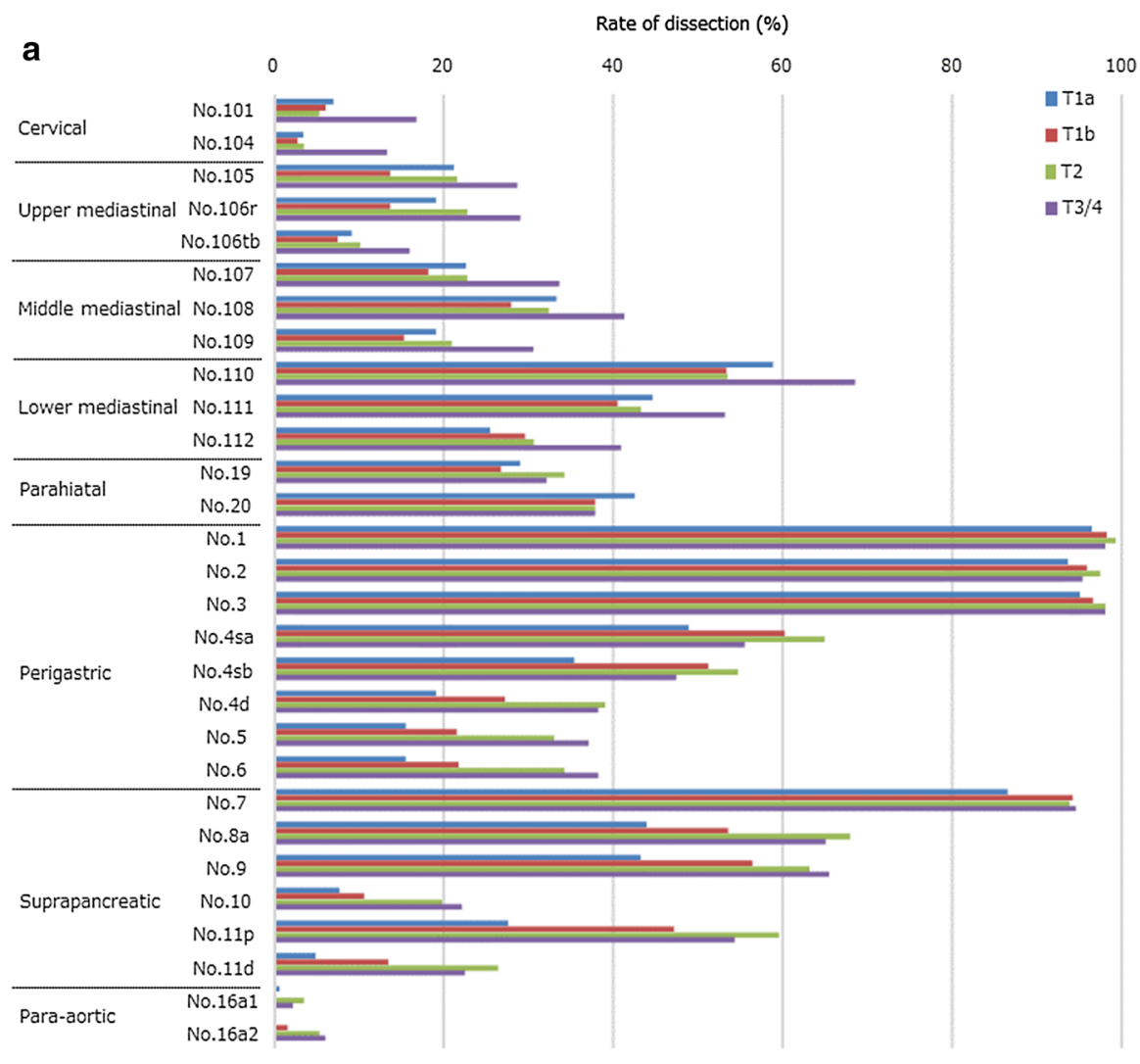

b Rate of dissection (\%)

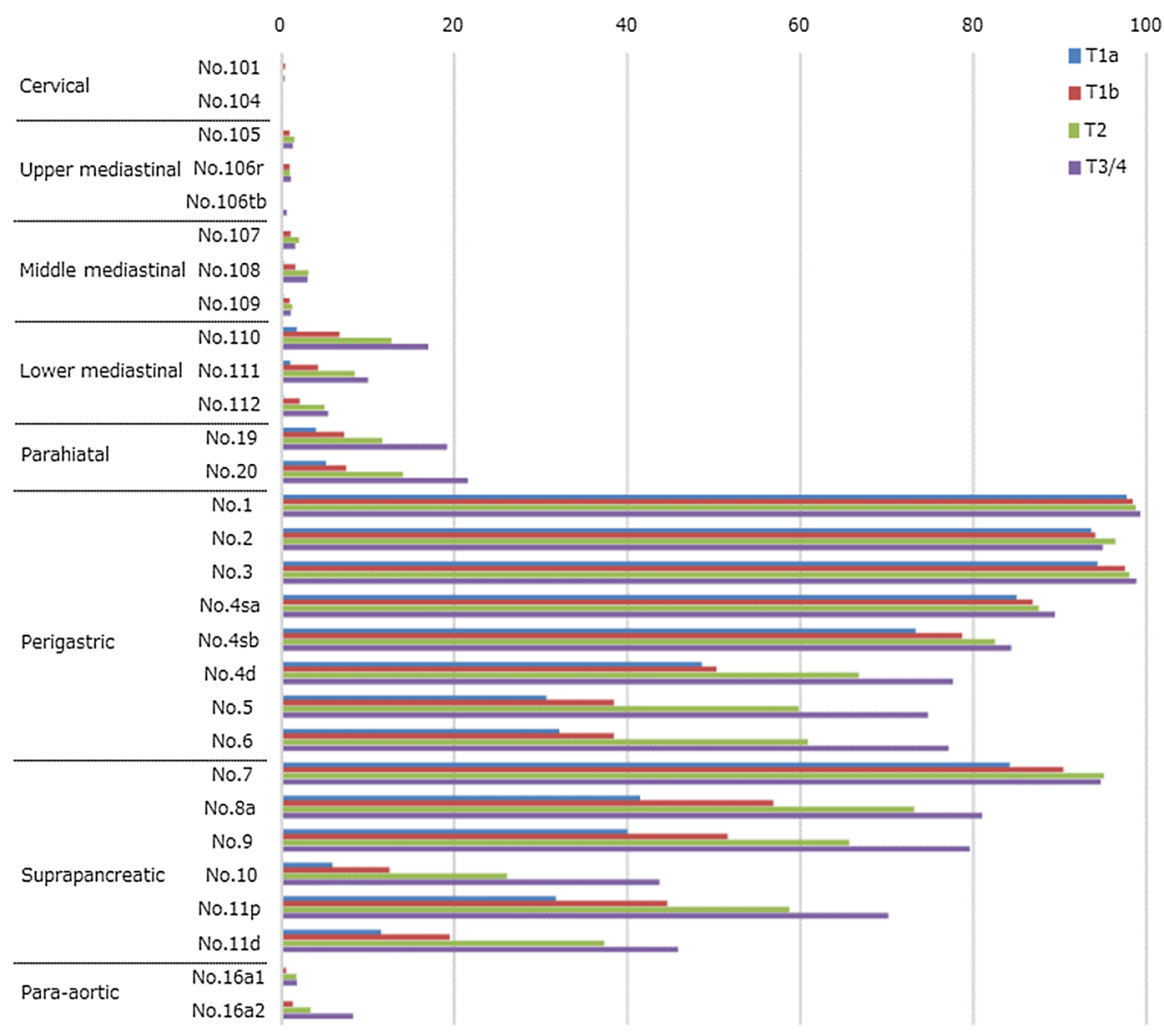


Fig. 2 continued

C

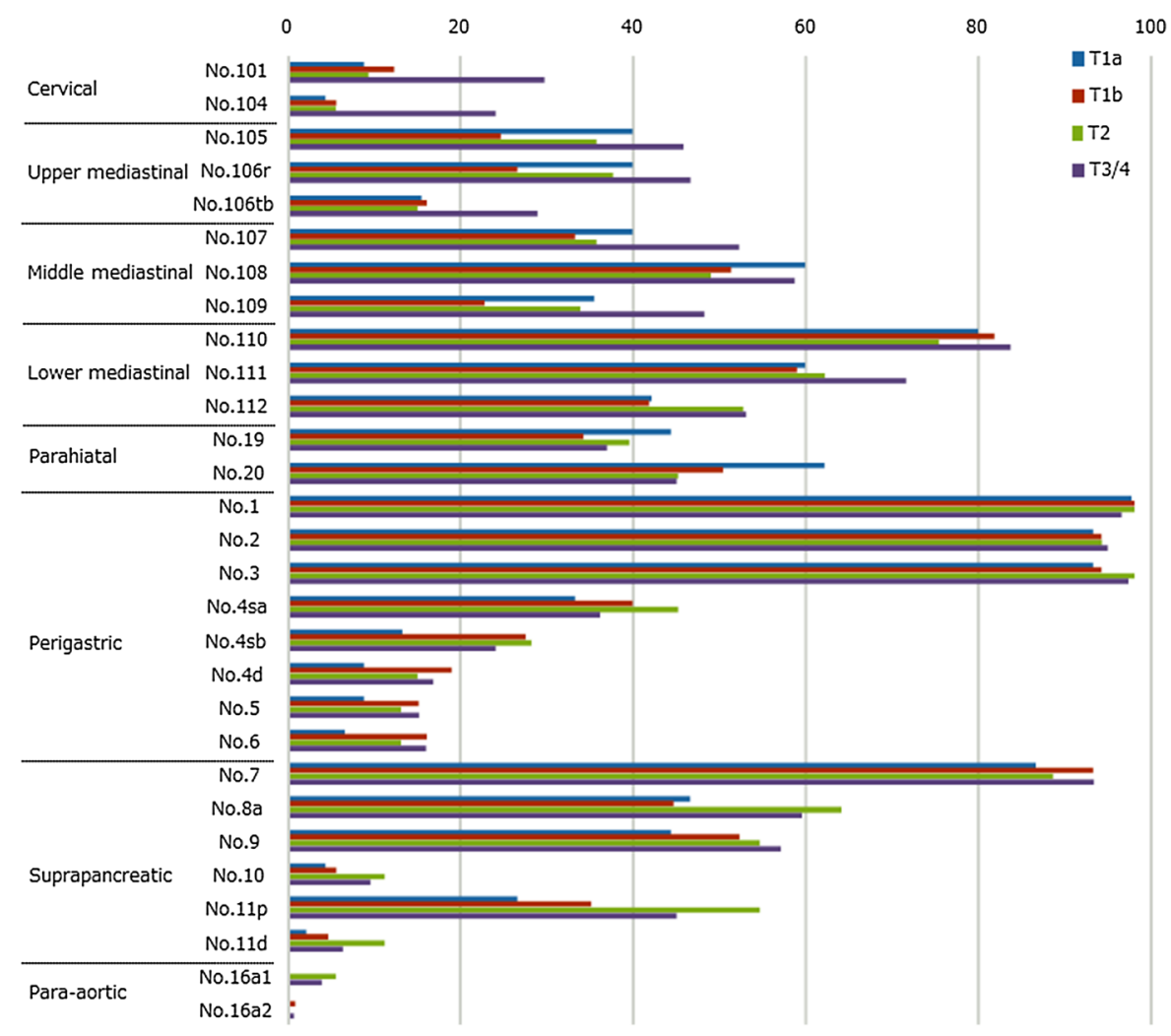

d

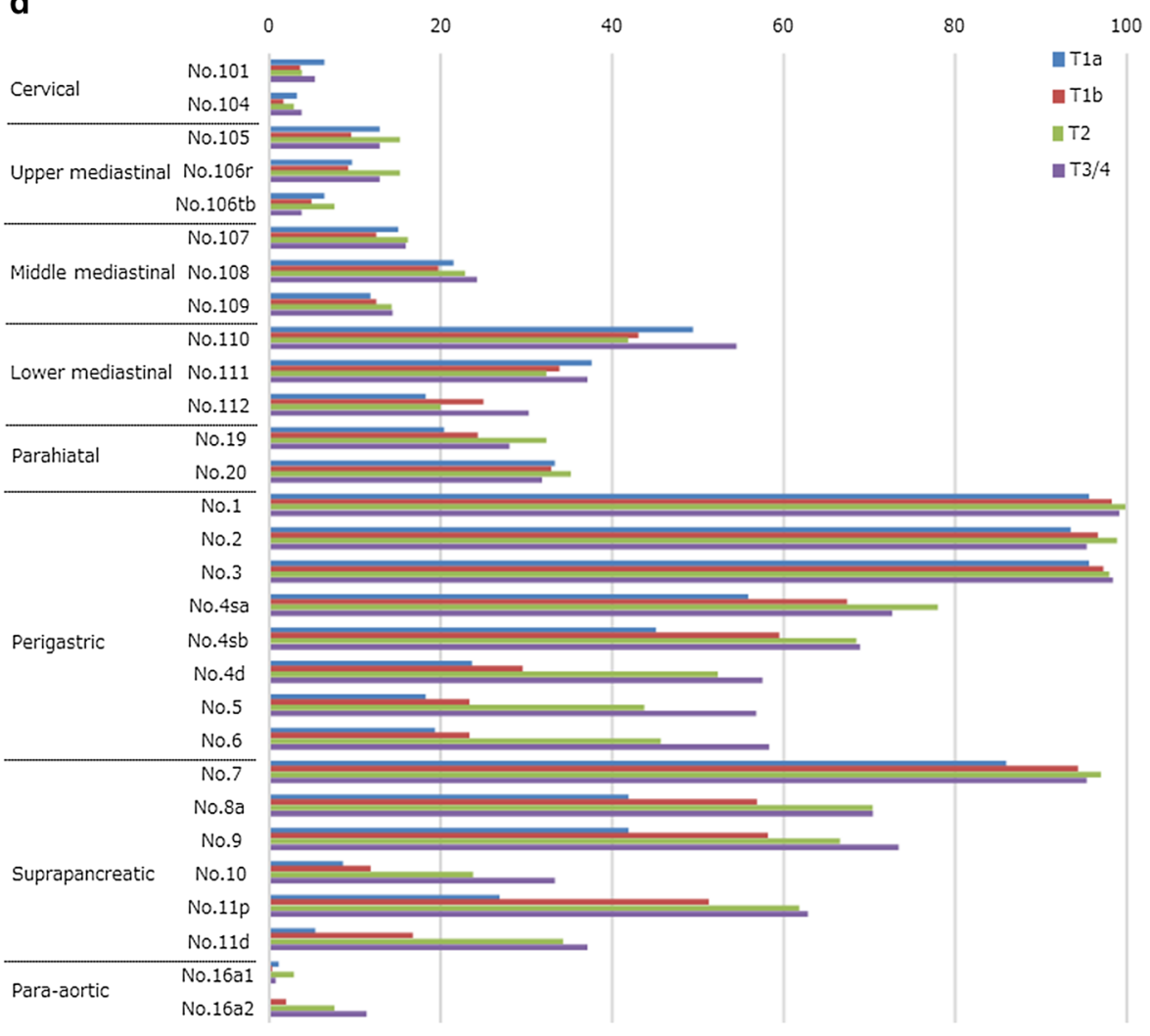


Fig. 3 Rates of lymph node metastasis at each station according to esophaguspredominant cancer (a) and stomach-predominant cancer (b) a

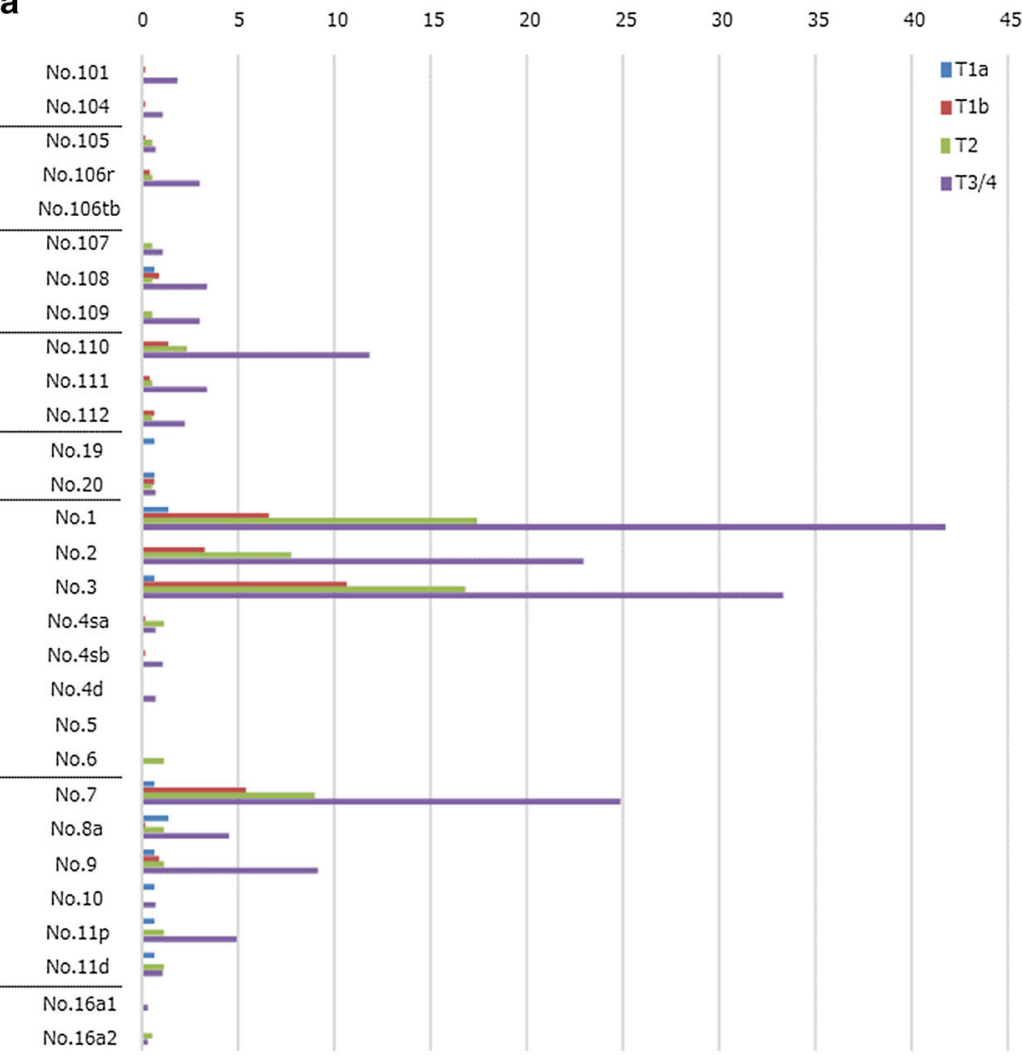

b

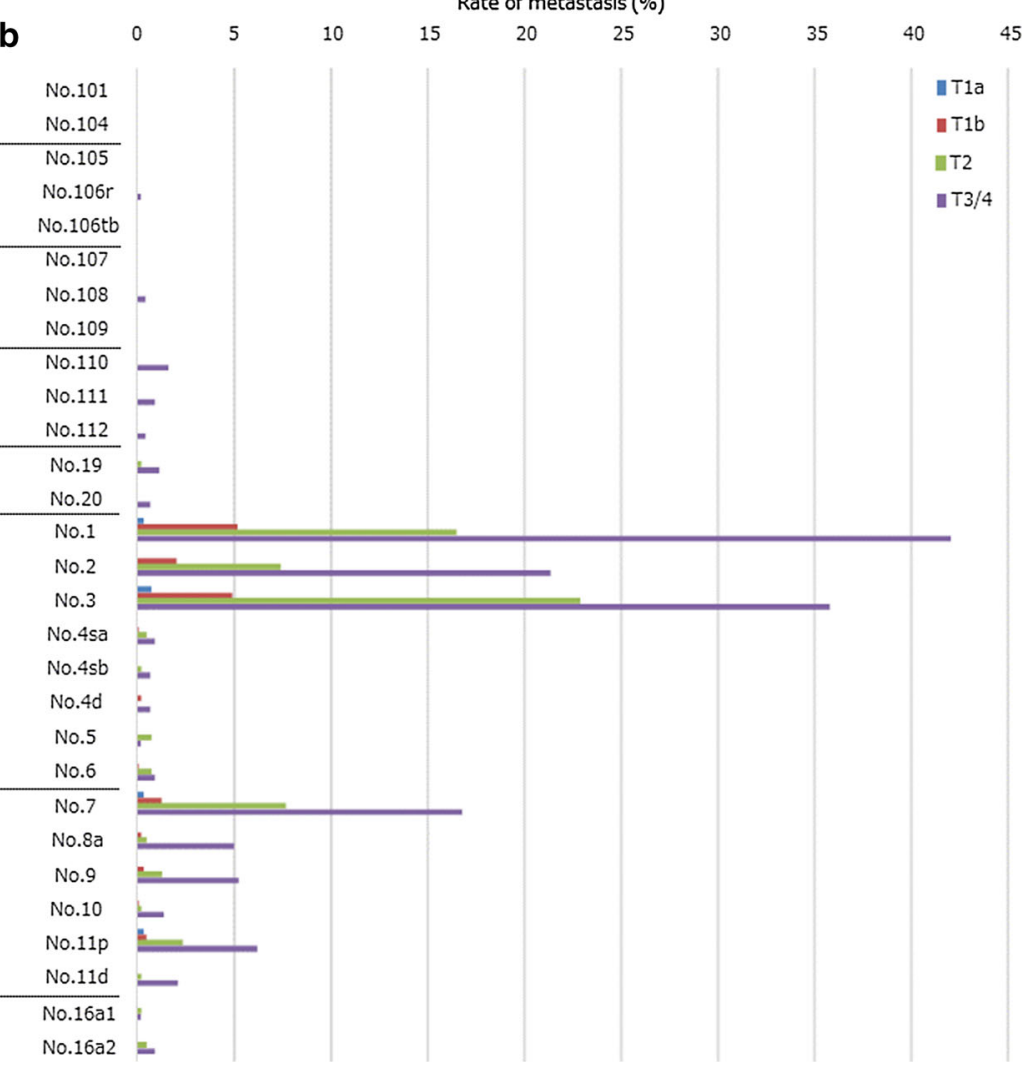




\section{Site of lymph node recurrence at the initial diagnosis of disease relapse}

Among 2754 patients with AC or SCC, 421 (15.3\%) developed recurrences during the follow-up period. Among these 421,189 patients had lymph node recurrence at the initial diagnosis of disease relapse. The abdominal paraaortic lymph node was the most frequent site of recurrence in both AC and SCC cases (Fig. 5). The region around the celiac artery was the second most common site, while mediastinal node recurrence was rather uncommon despite the low dissection rate in patients with stomach-predominant cancer. Mediastinal node recurrence was common in esophagus-predominant SCC and less common though similar to the celiac node recurrence rate in esophaguspredominant AC. It is noteworthy, however, that not only the metastatic rate in dissected nodes but also the nodal recurrence rate are higher in mediastinal nodes even with a higher dissection rate in esophagus-predominant cancer than in other types.

\section{Discussion}

While AC of the EGJ (AEG) has been increasing dramatically in Western countries in recent years, the number of operations for EGJ cancer has also gradually been rising in Japan as demonstrated in the present study population. There was a 2.4-fold increase in the number of operations for AEG during the decade targeted in this study. The trend for a rising rate of EGJ cancer in Japan was confirmed in the comprehensive registry of esophageal cancer during the same period [12-14]. Therefore, we appear to be witnessing a global event, and much more attention should be paid for this tumor entity.

This study clearly demonstrated differences in the nodal dissection rate among three subtypes of EGJ cancers and that various types of surgical procedure have been employed for EGJ cancers. The extents of nodal dissection differed remarkably even among tumors with the epicenter confined to within a very narrow range, $2 \mathrm{~cm}$ above to $2 \mathrm{~cm}$ below the EGJ. Therefore, the extent of esophagogastric resection is still a highly controversial topic for this tumor entity. The rates of lymph node dissection were very different between AC and SCC, even when tumor distributions were the same, as shown in Fig. 2c, d. This is consistent with a previous report from a single institute in Japan showing surgical procedures for EGJ carcinoma to differ between these two histological subtypes [15]. This is presumably attributable to the widely accepted belief that SCC originates from the squamous epithelium of the esophagus and therefore should, accordingly, be treated as an esophageal cancer. In fact, the tumor epicenters were proximal to the EGJ in most of the SCC cases in this study, and mediastinal nodal dissection was apparently more relevant in SCC than AC.

To the contrary, mediastinal lymph node dissection is not widely practiced, regardless of the tumor depth, while perigastric as well as suprapancreatic nodes were preferentially dissected in patients with stomach-predominant cancer. Total gastrectomy is apparently a rather common procedure in this population. Nevertheless, the incidences of metastasis at node nos. $4 \mathrm{sa}, 4 \mathrm{sb}, 4 \mathrm{~d}, 5$ and 6 were less than $1 \%$ even in patients with high dissection rates. Correspondingly, low index values of the estimated benefit of nodal dissection, according to these nodal stations, were confirmed. In light of previous studies wherein the benefits of prophylactic nodal dissection of this region were questionable [15-19], we can conclude that complete nodal clearance along the distal portion of the stomach offers only a marginal survival benefit and is not essential for local control of the disease in this population. The clinical importance of undergoing a total gastrectomy is partly related to more comprehensive lymph node staging, but more importantly with expected impaired QOL after esophagogastrostomy in the mediastinum.

The optimal treatment strategy for esophagus-predominant AC remains highly controversial. Mediastinal node dissection, especially upper and middle mediastinal, was less relevant in AC than in SCC patients, even when the anatomical tumor locations were the same. Therefore, in this study, we encountered an unavoidable limitation when assessing the prognostic impact of mediastinal lymph node dissection beyond the lower mediastinum in esophaguspredominant AC, although incidence of lymph node recurrence in the middle and upper mediastinum was low. The low dissection rates of upper and middle mediastinal nodes presumably reflect esophageal AC having long been a much rarer malignancy than esophageal SCC in Japan, and we can reasonably assume that AEG has been widely regarded as a form of gastric AC.

As might be expected given the very low incidence of metastasis, dissection of distal perigastric nodes is also unlikely to be beneficial in terms of survival for esophagus-predominant AC. Esophagus-predominant AC had a higher dissection rate, metastatic incidences and therapeutic index values of lower mediastinal nodes, equivalent to those of suprapancreatic nodes (nos. 9 and 11p), than stomach-predominant cancer. Therefore, lower mediastinal nodes showed a metastatic incidence and therapeutic index similar to those of suprapancreatic nodes (nos. 9, 11p and 11d). This result may basically support the oncologic outcomes of extended esophagectomy and total gastrectomy being similar [20, 21], since the aforementioned lymph node stations can be dissected during either procedure. 
a

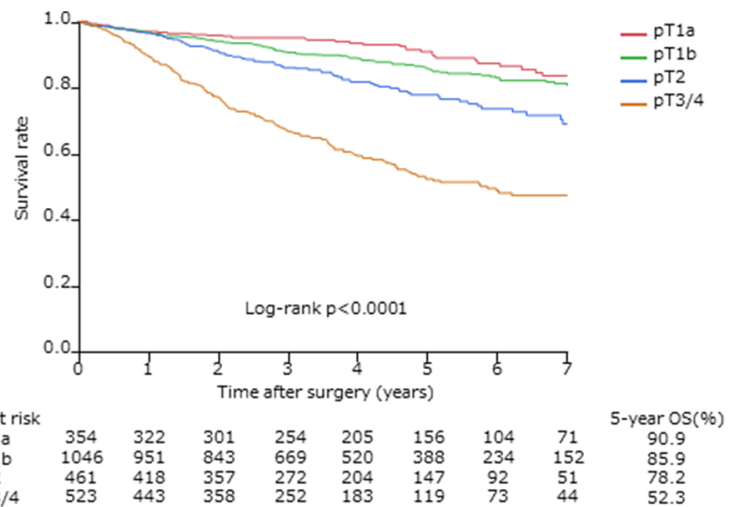

C

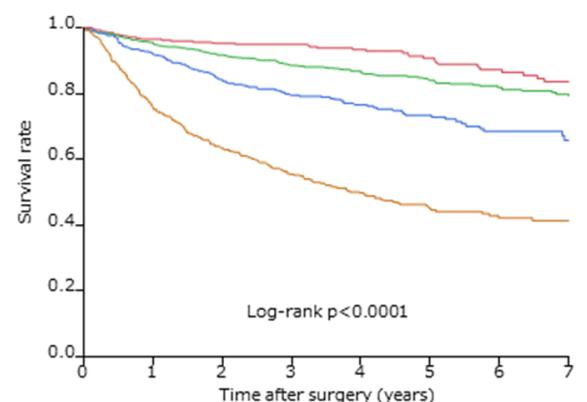

Number at risk

$\begin{array}{lllllllllc} & \\ \text { Tia } & 354 & 319 & 299 & 253 & 205 & 156 & 103 & 71 & 5 \text {-year RFS(\%) } \\ \text { T1b } & 1046 & 937 & 823 & 652 & 507 & 379 & 232 & 149 & 83.6 \\ \text { T2 } & 461 & 400 & 331 & 251 & 188 & 135 & 83 & 45 & 73.2 \\ T 3 / 4 & 523 & 382 & 304 & 216 & 159 & 104 & 65 & 38 & 44.9\end{array}$

e

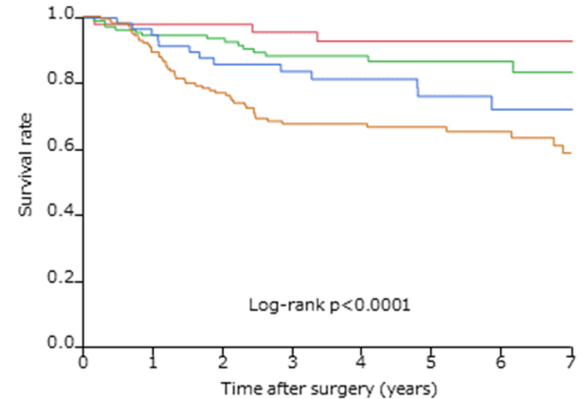

- ${ }^{\mathrm{pT} 1 \mathrm{a}}$

二

二 $\mathrm{PT} 3 / 4$

Number at risk

$\begin{array}{llllllllll}\text { T1a } & 49 & 48 & 47 & 37 & 31 & 25 & 16 & 6 & 5 \text {-year OS(\%) } \\ \text { T1 } & 11.8 & 105 & 98 & 75 & 58 & 43 & 28 & 18 & 869\end{array}$

$\begin{array}{llllllllll}\text { T1a } & 49 & 48 & 47 & 37 & 31 & 25 & 16 & 6 & 92.8 \\ \text { T1b } & 116 & 105 & 98 & 75 & 58 & 43 & 28 & 18 & 86.9 \\ \text { T2 } & 61 & 56 & 46 & 37 & 35 & 28 & 18 & 15 & 76.2 \\ \text { T3/4 } & 144 & 125 & 104 & 82 & 68 & 56 & 40 & 25 & 66.4\end{array}$

g

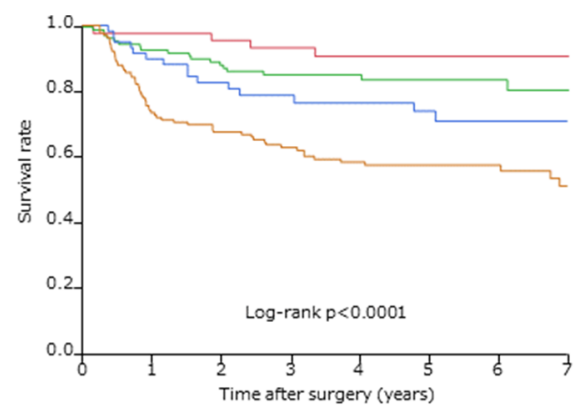

Number at risk

$\begin{array}{lccccccccc}\text { T1a } & 49 & 48 & 46 & 37 & 31 & 25 & 16 & 6 & 5 \text {-year RFS(\%) } \\ \text { T1b } & 116 & 104 & 93 & 72 & 57 & 43 & 28 & 18 & 83.7 \\ \text { T2 } & 61 & 53 & 44 & 35 & 34 & 28 & 18 & 15 & 73.9 \\ \text { T3/4 } & 144 & 103 & 93 & 77 & 63 & 52 & 37 & 22 & 57.5\end{array}$

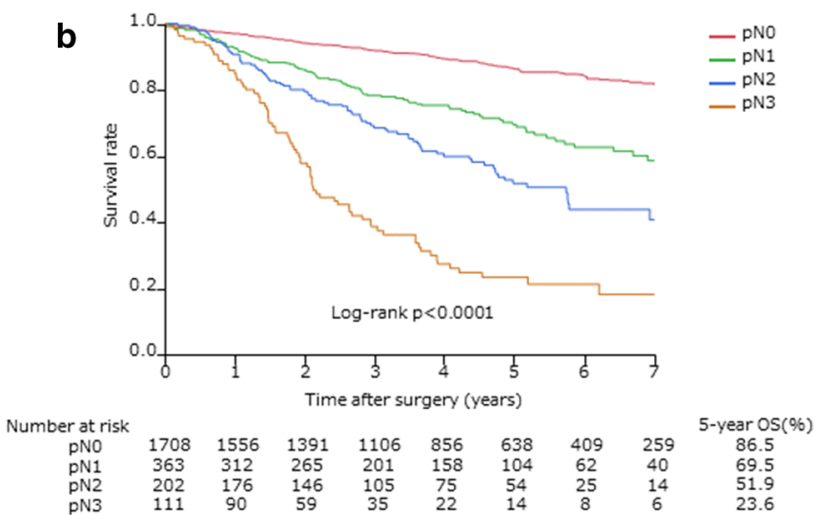

d

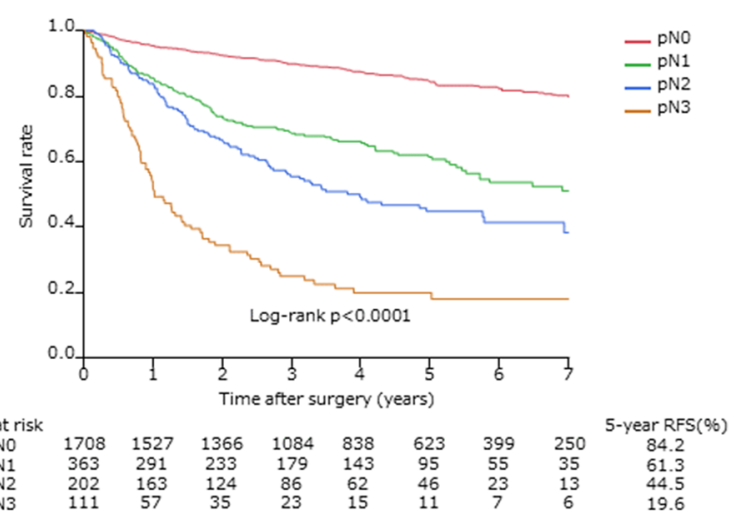

f

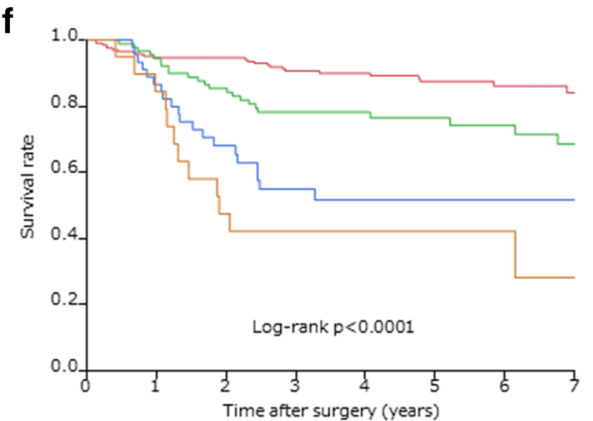
$\begin{array}{cccccccccc}\text { Number at risk } & & & & & & & \\ \text { pNO } & 208 & 192 & 183 & 148 & 121 & 93 & 62 & 37 & 5 \text {-year OS(\%) } \\ \text { pN1 } & 93 & 84 & 74 & 58 & 49 & 38 & 27 & 19 & 76.3 \\ \text { pN2 } & 48 & 40 & 28 & 18 & 15 & 14 & 8 & 5 & 51.8 \\ \text { pN3 } & 21 & 17 & 10 & 7 & 7 & 6 & 5 & 2 & 42.2\end{array}$

\section{h}

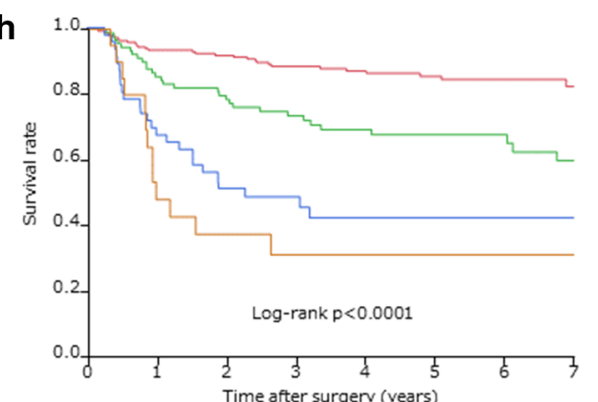

Number at risk 5 -year RFS(\%)

$\begin{array}{cccccccccc}\text { Number at risk } & & & & & & & & & \\ \mathrm{pNO} & 208 & 190 & 178 & 144 & 118 & 92 & 61 & 36 & 5 \text {-year } \mathrm{RFS}(\%) \\ \mathrm{pN1} & 93 & 76 & 68 & 55 & 47 & 37 & 27 & 18 & 68.0 \\ \mathrm{pN2} & 48 & 32 & 22 & 16 & 14 & 13 & 7 & 4 & 42.1\end{array}$

$\begin{array}{llllllllll}\mathrm{pN} 2 & 48 & 32 & 22 & 16 & 14 & 13 & 7 & 4 & 42.1 \\ \mathrm{pN3} & 21 & 10 & 8 & 6 & 6 & 5 & 4 & 2 & 31.1\end{array}$ 
4Fig. 4 Overall survival curve for patients with adenocarcinoma of the esophagogastric junction according to the pT stage (a); according to the $\mathrm{pN}$ stage (b); recurrence-free survival curve for patients with adenocarcinoma of the esophagogastric junction according to the $\mathrm{pT}$ stage (c); according to the $\mathrm{pN}$ stage (d); overall survival curve of patients with squamous cell carcinoma of the esophagogastric junction according to the $\mathrm{pT}$ stage (e); according to the $\mathrm{pN}$ stage (f); recurrence-free survival curve of patients with squamous cell carcinoma of the esophagogastric junction according to the pT stage (g); according to the $\mathrm{pN}$ stage (h)

Notably, calculated therapeutic index values for nodes in the cervical, upper and middle mediastinum were equivalent to those of node nos. 7, 9 and 110 in patients with esophagus-predominant SCC. Dissection of these regions was not routine, instead being rather selective according to the dissection rates shown in Fig. 2c, and the absolute number of patients with metastasis involving these regions was not large. Interestingly, the $\mathrm{pN}$ stage was $\mathrm{pN} 1$ in $9, \mathrm{pN} 2$ in 7 and $\mathrm{pN} 3$ in 9 patients, respectively, among the 25 with metastatic involvement in the cervical, upper and/or middle mediastinal nodes. Even though metastasis to these nodes is not always associated with progressive nodal disease in patients with esophagus-predominant SCC, dissecting these nodes might still be of benefit if the number of metastatic nodes in these areas is small. This speculation is supported by the evidence that sentinel nodes are widely distributed among subcarinal, lower thoracic paraesophageal, pericardial and lesser curvature nodes, as well as those along the left gastric artery, in patients with cancers located in sites ranging from the abdominal esophagus to the EGJ [22].

Suprapancreatic nodes, nos. 8a, 9, 11p and 11d, are reasonable targets for dissection given the incidence of metastasis and therapeutic values, although there are some disparities in index values among the three sub-groups in this study. The index value of the splenic hilum node (no. 10) was 0 in esophagus-predominant $\mathrm{AC}$, and none of the patients with esophagus-predominant SCC had metastasis at this station. Although some patients with stomach-predominant cancer and concomitant no. 10 node metastasis showed prolonged survival after surgery, splenectomy aiming at complete node clearance cannot be regarded as a viable option, according to a recent randomized trial [23].

Lymph node status was found to be the most powerful prognostic determinant for both AC and SCC in this study. Most notably, pN3 disease was definitely associated with short RFS and low OS rates, and the propensity for extensive nodal disease, regardless of histology, seems likely to negate the potential benefits of more radical surgery with extensive nodal dissection. This finding is essentially consistent with a previous report showing the probability of systemic disease after R0 esophagectomy to approach $100 \%$ when the number of involved nodes exceeds eight in esophageal AC or SCC [24]. We can speculate that the potential benefit of an extended lymphadenectomy is dependent upon the number of positive lymph nodes. Therefore, an optimal treatment strategy might emphasize systemic therapy, rather than the extent of lymph node dissection, for patients with extended nodal disease. Although complete tumor removal is the therapeutic mainstay and is indicated in the absence of distant metastasis, neoadjuvant therapy might be advantageous for patients with node-positive EGJ cancer, even when clinically resectable, as demonstrated in a randomized trial obtaining a definite survival advantage with neoadjuvant chemoradiotherapy for cT1N1 and cT2-3N0-1 disease [25].

The abdominal para-aortic node is the most frequent site of recurrence, as described in previous reports [16, 26, 27]. This result might be supported by the observation that the lymphatic pathway from the cardia is mainly downward along the inferior phrenic vessels to the para-celiac and para-aortic nodes, according to experimental and clinical findings [28]. Interestingly, however, the mode of lymph node recurrence in esophagus-predominant $\mathrm{AC}$ is similar to that in esophagus-predominant SCC rather than the mode in stomach-predominant cancer. The esophagus has a distinct lymphatic system that runs longitudinally along the submucosal dense plexus and perpendicularly to regional lymph nodes or the thoracic duct [29]. Therefore, it might be interesting to study whether esophagus-predominant EGJ cancers show a lymphatic spread pattern identical to that defined by the topographic tumor location in the esophagus, independently of tumor histology.

More than $90 \%$ of all metastatic nodes in this study were confirmed to be confined to the nodes along the proximal portion of the stomach, esophageal hiatus, distal esophagus and suprapancreatic area (data not shown). Taking all features into account, proximal gastrectomy (plus lower esophagectomy for esophagus-predominant cancer) can reasonably encompass nodes likely to be involved in EGJ cancers, and this would presumably be a minimum requirement. Whether this approach is feasible in terms of clinical outcomes, mortality and morbidity and restores patient QOL, as compared with other extended procedures for advanced small EGJ cancers, is an interesting issue that merits further study.

Our algorithm was established to provide a tentative standard for lymphadenectomy in EGJ cancer [30] based on the intermediate results of this study, though suffering from unavoidable limitations due to the nature of a retrospective multi-institutional study. The final results of this study do not alter the recommendations, and this preliminary algorithm might serve as the basis for proposing specific approaches and tailoring the extent of lymph node dissection as well as that of esophagogastric resection for individual patients with EGJ cancer. 
Table 2 Incidence, 5-year survival rate and calculated index of estimated benefit from lymph node dissection in esophagogastric junction carcinoma

\begin{tabular}{|c|c|c|c|c|c|c|c|c|}
\hline \multirow[t]{2}{*}{ Nodal station } & \multicolumn{2}{|c|}{$\begin{array}{l}\text { Number of patients } \\
\text { with metastatic nodes }\end{array}$} & \multicolumn{2}{|c|}{$\begin{array}{l}\text { Rate of lymph node } \\
\text { metastasis }(\%)\end{array}$} & \multicolumn{2}{|c|}{$\begin{array}{l}\text { 5-YSR of patients with } \\
\text { metastatic nodes }(\%)\end{array}$} & \multicolumn{2}{|l|}{ Index } \\
\hline & $\begin{array}{l}\mathrm{T} 1 \\
n=397\end{array}$ & $\begin{array}{l}\mathrm{T} 2 \\
n=237\end{array}$ & $\begin{array}{l}\text { T1 } \\
n=397\end{array}$ & $\begin{array}{l}\mathrm{T} 2 \\
n=237\end{array}$ & $\begin{array}{l}\mathrm{T} 1 \\
n=397\end{array}$ & $\begin{array}{l}\mathrm{T} 2 \\
n=237\end{array}$ & $\begin{array}{l}\text { T1 } \\
n=397\end{array}$ & $\begin{array}{l}\mathrm{T} 2 \\
n=237\end{array}$ \\
\hline \multicolumn{9}{|c|}{ Esophagus-predominant adenocarcinoma of esophagogastric junction } \\
\hline No. 101 & 0 & 0 & 0.0 & 0.0 & NA & NA & & \\
\hline No. 104 & 0 & 0 & 0.0 & 0.0 & NA & NA & & \\
\hline No. 105 & 1 & 1 & 0.3 & 0.4 & NR & NR & & \\
\hline No. $106 \mathrm{r}$ & 1 & 0 & 0.3 & 0.0 & 0 & NA & 0.0 & \\
\hline No. 106 tb & 0 & 0 & 0.0 & 0.0 & NA & NA & & \\
\hline No. 107 & 0 & 1 & 0.0 & 0.4 & NA & 100 & & 2.6 \\
\hline No. 108 & 3 & 3 & 0.8 & 1.3 & 66.7 & 0 & 2.5 & 0.0 \\
\hline No. 109 & 0 & 4 & 0.0 & 1.7 & NA & 0 & & 0.0 \\
\hline No. 110 & 2 & 12 & 0.5 & 5.1 & 100 & 18.3 & 1.1 & 1.9 \\
\hline No. 111 & 1 & 4 & 0.3 & 1.7 & 0 & 25 & 0.0 & 1.2 \\
\hline No. 112 & 2 & 3 & 0.5 & 1.3 & 50 & 0 & 1.1 & 0.0 \\
\hline No. 19 & 1 & 0 & 0.3 & 0.0 & 0 & NA & 0.0 & \\
\hline No. 20 & 3 & 0 & 0.8 & 0.0 & 33.3 & NA & 0.8 & \\
\hline No. 1 & 20 & 82 & 5.0 & 34.6 & 68.3 & 26.5 & 3.5 & 9.2 \\
\hline No. 2 & 8 & 39 & 2.0 & 16.5 & 68.6 & 33.9 & 1.4 & 5.7 \\
\hline No. 3 & 28 & 68 & 7.1 & 28.7 & 68.2 & 45.8 & 5.0 & 13.4 \\
\hline No. 4sa & 1 & 3 & 0.3 & 1.3 & NR & NR & & \\
\hline No. $4 \mathrm{sb}$ & 1 & 3 & 0.3 & 1.3 & 0 & 66.7 & 0.0 & 1.2 \\
\hline No. $4 \mathrm{~d}$ & 0 & 2 & 0.0 & 0.8 & NA & NR & & \\
\hline No. 5 & 0 & 0 & 0.0 & 0.0 & NA & NA & & \\
\hline No. 6 & 0 & 2 & 0.0 & 0.8 & NA & NR & & \\
\hline No. 7 & 15 & 42 & 3.8 & 17.7 & 69.2 & 26.0 & 2.8 & 4.8 \\
\hline No. $8 \mathrm{a}$ & 2 & 9 & 0.5 & 3.8 & 50 & 16.7 & 0.5 & 0.9 \\
\hline No. 9 & 4 & 16 & 1.0 & 6.8 & 75 & 40.6 & 1.4 & 3.9 \\
\hline No. 10 & 1 & 2 & 0.3 & 0.8 & 0 & 0 & 0.0 & 0.0 \\
\hline No. $11 p$ & 1 & 10 & 0.3 & 4.2 & 0 & 49.2 & 0.0 & 3.3 \\
\hline No. $11 \mathrm{~d}$ & 1 & 5 & 0.3 & 2.1 & 0 & 40 & 0.0 & 2.4 \\
\hline No. $16 a 1$ & 0 & 0 & 0.0 & 0.0 & NA & NA & & \\
\hline \multirow[t]{2}{*}{ No. $16 \mathrm{a} 2$} & 0 & 2 & 0.0 & 0.8 & NA & NR & & \\
\hline & $\begin{array}{l}\mathrm{T} 1 \\
n=150\end{array}$ & $\begin{array}{l}\mathrm{T} 2 \\
n=177\end{array}$ & $\begin{array}{l}\mathrm{T} 1 \\
n=150\end{array}$ & $\begin{array}{l}\text { T2 } \\
n=177\end{array}$ & $\begin{array}{l}\mathrm{T} 1 \\
n=150\end{array}$ & $\begin{array}{l}\mathrm{T} 2 \\
n=177\end{array}$ & $\begin{array}{l}\mathrm{T} 1 \\
n=150\end{array}$ & $\begin{array}{l}\text { T2 } \\
n=177\end{array}$ \\
\hline \multicolumn{9}{|c|}{ Esophagus-predominant squamous cell carcinoma of esophagogastric junction } \\
\hline No. 101 & 1 & 5 & 0.7 & 2.8 & 100 & 80 & 5.9 & 9.5 \\
\hline No. 104 & 1 & 3 & 0.7 & 1.7 & 100 & 66.7 & 12.5 & 6.1 \\
\hline No. 105 & 0 & 2 & 0.0 & 1.1 & NA & NR & & \\
\hline No. $106 \mathrm{r}$ & 1 & 9 & 0.7 & 5.1 & 100 & 42.9 & 2.2 & 5.0 \\
\hline No. 106tb & 0 & 0 & 0.0 & 0.0 & NA & NA & & \\
\hline No. 107 & 0 & 3 & 0.0 & 1.7 & NA & 33.3 & & 1.2 \\
\hline No. 108 & 2 & 7 & 1.3 & 4.0 & NR & 28.6 & & 2.0 \\
\hline No. 109 & 0 & 5 & 0.0 & 2.8 & NA & 60 & & 3.8 \\
\hline No. 110 & 4 & 21 & 2.7 & 11.9 & 100 & 53.2 & 3.3 & 7.8 \\
\hline No. 111 & 1 & 6 & 0.7 & 3.4 & 100 & 0 & 1.1 & 0.0 \\
\hline No. 112 & 0 & 4 & 0.0 & 2.3 & NA & 25 & & 1.1 \\
\hline
\end{tabular}


Table 2 continued

\begin{tabular}{|c|c|c|c|c|c|c|c|c|}
\hline & $\begin{array}{l}\mathrm{T} 1 \\
n=150\end{array}$ & $\begin{array}{l}\mathrm{T} 2 \\
n=177\end{array}$ & $\begin{array}{l}\mathrm{T} 1 \\
n=150\end{array}$ & $\begin{array}{l}\mathrm{T} 2 \\
n=177\end{array}$ & $\begin{array}{l}\mathrm{T} 1 \\
n=150\end{array}$ & $\begin{array}{l}\mathrm{T} 2 \\
n=177\end{array}$ & $\begin{array}{l}\mathrm{T} 1 \\
n=150\end{array}$ & $\begin{array}{l}\mathrm{T} 2 \\
n=177\end{array}$ \\
\hline No. 19 & 0 & 0 & 0.0 & 0.0 & NA & NA & & \\
\hline No. 20 & 1 & 3 & 0.7 & 1.7 & 0 & NR & 0.0 & \\
\hline No. 1 & 10 & 53 & 6.7 & 29.9 & 87.5 & 45.3 & 6.0 & 14.0 \\
\hline No. 2 & 6 & 34 & 4.0 & 19.2 & 100 & 62 & 4.3 & 12.5 \\
\hline No. 3 & 16 & 43 & 10.7 & 24.3 & 92.9 & 53.8 & 10.5 & 13.4 \\
\hline No. 4sa & 0 & 1 & 0.0 & 0.6 & NA & NR & & \\
\hline No. $4 \mathrm{sb}$ & 0 & 0 & 0.0 & 0.0 & NA & NA & & \\
\hline No. $4 \mathrm{~d}$ & 0 & 0 & 0.0 & 0.0 & NA & NA & & \\
\hline No. 5 & 0 & 0 & 0.0 & 0.0 & NA & NA & & \\
\hline No. 6 & 0 & 0 & 0.0 & 0.0 & NA & NA & & \\
\hline No. 7 & 9 & 38 & 6.0 & 21.5 & 77.8 & 45.3 & 5.1 & 10.6 \\
\hline No. 8a & 1 & 5 & 0.7 & 2.8 & NR & 60 & & 2.8 \\
\hline No. 9 & 1 & 10 & 0.7 & 5.6 & 0 & 63.5 & 0.0 & 6.4 \\
\hline No. 10 & 0 & 0 & 0.0 & 0.0 & NA & NA & & \\
\hline No. $11 p$ & 0 & 4 & 0.0 & 2.3 & NA & 50 & & 2.4 \\
\hline No. $11 \mathrm{~d}$ & 0 & 0 & 0.0 & 0.0 & NA & NA & & \\
\hline No. 16a1 & 0 & 1 & 0.0 & 0.6 & NA & 100 & & 12.5 \\
\hline \multirow[t]{2}{*}{ No. $16 a 2$} & 0 & 0 & 0.0 & 0.0 & NA & NA & & \\
\hline & $\begin{array}{l}\text { T1 } \\
n=1018\end{array}$ & $\begin{array}{l}\mathrm{T} 2 \\
n=775\end{array}$ & $\begin{array}{l}\text { T1 } \\
n=1018\end{array}$ & $\begin{array}{l}\mathrm{T} 2 \\
n=775\end{array}$ & $\begin{array}{l}\mathrm{T} 1 \\
n=1018\end{array}$ & $\begin{array}{l}\text { T2 } \\
n=775\end{array}$ & $\begin{array}{l}\text { T1 } \\
n=1018\end{array}$ & $\begin{array}{l}\text { T2 } \\
n=775\end{array}$ \\
\hline \multicolumn{9}{|c|}{ Stomach-predominant carcinoma of esophagogastric junction } \\
\hline No. 101 & 0 & 0 & 0.0 & 0.0 & NA & NA & & \\
\hline No. 104 & 0 & 0 & 0.0 & 0.0 & NA & NA & & \\
\hline No. 105 & 0 & 0 & 0.0 & 0.0 & NA & NA & & \\
\hline No. 106r & 0 & 1 & 0.0 & 0.1 & NA & 0 & & 0.0 \\
\hline No. 106tb & 0 & 0 & 0.0 & 0.0 & NA & NA & & \\
\hline No. 107 & 0 & 0 & 0.0 & 0.0 & NA & NA & & \\
\hline No. 108 & 0 & 2 & 0.0 & 0.3 & NA & 0 & & 0.0 \\
\hline No. 109 & 0 & 0 & 0.0 & 0.0 & NA & NA & & \\
\hline No. 110 & 0 & 7 & 0.0 & 0.9 & NA & 0 & & 0.0 \\
\hline No. 111 & 0 & 4 & 0.0 & 0.5 & NA & 0 & & 0.0 \\
\hline No. 112 & 0 & 2 & 0.0 & 0.3 & NA & NR & & \\
\hline No. 19 & 0 & 6 & 0.0 & 0.8 & NA & 62.5 & & 3.1 \\
\hline No. 20 & 0 & 3 & 0.0 & 0.4 & NA & 0 & & 0.0 \\
\hline No. 1 & 41 & 236 & 4.0 & 30.5 & 72.4 & 43.5 & 3.0 & 13.4 \\
\hline No. 2 & 16 & 116 & 1.6 & 15.0 & 93.8 & 46.3 & 1.6 & 7.2 \\
\hline No. 3 & 40 & 229 & 3.9 & 29.5 & 77.2 & 50.7 & 3.1 & 15.2 \\
\hline No. 4sa & 1 & 6 & 0.1 & 0.8 & NR & 62.5 & & 0.5 \\
\hline No. $4 \mathrm{sb}$ & 0 & 4 & 0.0 & 0.5 & NA & NR & & \\
\hline No. $4 \mathrm{~d}$ & 2 & 3 & 0.2 & 0.4 & 100 & 66.7 & 0.4 & 0.4 \\
\hline No. 5 & 0 & 4 & 0.0 & 0.5 & NA & 0 & & 0.0 \\
\hline No. 6 & 1 & 7 & 0.1 & 0.9 & NR & 42.9 & & 0.6 \\
\hline No. 7 & 11 & 97 & 1.1 & 12.5 & 85.7 & 35.5 & 1.0 & 4.7 \\
\hline No. $8 \mathrm{a}$ & 2 & 23 & 0.2 & 3.0 & NR & 27.5 & & 1.1 \\
\hline No. 9 & 3 & 27 & 0.3 & 3.5 & 100 & 16.2 & 0.6 & 0.8 \\
\hline No. 10 & 1 & 7 & 0.1 & 0.9 & 100 & 42.9 & 0.9 & 1.1 \\
\hline No. $11 p$ & 5 & 35 & 0.5 & 4.5 & 50 & 39.4 & 0.6 & 2.8 \\
\hline
\end{tabular}


Table 2 continued

\begin{tabular}{|c|c|c|c|c|c|c|c|c|}
\hline & $\begin{array}{l}\text { T1 } \\
n=1018\end{array}$ & $\begin{array}{l}\mathrm{T} 2 \\
n=775\end{array}$ & $\begin{array}{l}\text { T1 } \\
n=1018\end{array}$ & $\begin{array}{l}\mathrm{T} 2 \\
n=775\end{array}$ & $\begin{array}{l}\mathrm{T} 1 \\
n=1018\end{array}$ & $\begin{array}{l}\mathrm{T} 2 \\
n=775\end{array}$ & $\begin{array}{l}\mathrm{T} 1 \\
n=1018\end{array}$ & $\begin{array}{l}\mathrm{T} 2 \\
n=775\end{array}$ \\
\hline No. $11 \mathrm{~d}$ & 0 & 10 & 0.0 & 1.3 & NA & 53.3 & & 1.7 \\
\hline No. $16 \mathrm{a} 1$ & 0 & 2 & 0.0 & 0.3 & NA & 50 & & 6.7 \\
\hline No. $16 a 2$ & 0 & 5 & 0.0 & 0.6 & NA & 0 & & 0.0 \\
\hline
\end{tabular}

Lymph node stations are defined as: 101 cervical paraesophageal, 104 supraclavicular, 105 upper thoracic paraesophageal, $106 r$ along the recurrent nerve, $106 \mathrm{tb}$ tracheobronchial, 107 subcarinal, 108 middle thoracic paraesophageal, 109 along the main bronchus, 110 lower thoracic paraesophageal, 111 supradiaphragmatic, 112 posterior mediastinal, 19 infradiaphragmatic, 20 along the esophageal hiatus, 1 right cardial, 2 left cardial, 3 lesser curvature, $4 s a$ along the short gastric artery, $4 s b$ along the left gastroepiploic artery, $4 d$ along the right gastroepiploic, 5 suprapyloric, 6 infrapyloric, 7 along the left gastric artery, $8 a$ along the common hepatic artery (anterosuperior side), 9 along the celiac artery, 10 splenic hilum, $11 \mathrm{p}$ along the proximal splenic artery, $11 \mathrm{~d}$ along the distal splenic artery, $16 \mathrm{a} 1$ along the aortic hiatus, $16 a 2$ around the abdominal aorta (from the upper margin of the celiac trunk to the lower margin of the left renal vein), $N A$ indicates not analyzed, $N R$ indicates all patients with metastatic nodes followed up less than 5 years, 5-YSR is the 5-year overall survival rate

Fig. 5 Site of lymph node recurrence at the initial diagnosis of disease relapse

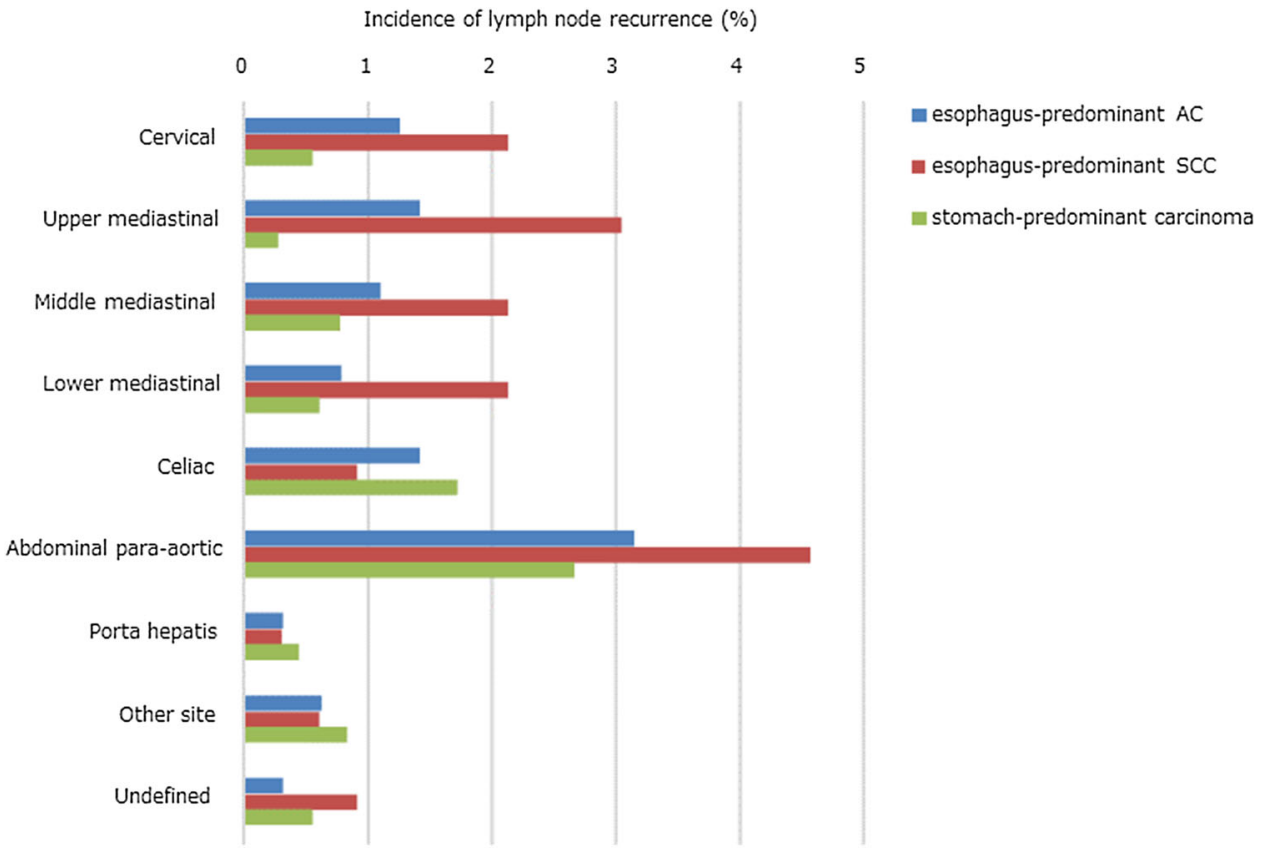

Prophylactic lymph node dissection around the distal stomach is unlikely to be essential for EGJ cancers less than $4 \mathrm{~cm}$ in diameter. Extents of esophageal resection and mediastinal lymph node dissection remain to be determined for esophagus-predominant EGJ cancers. Further evaluation of the optimal range of surgical intervention is warranted, especially for large EGJ cancers.

Acknowledgements We thank all surgeons who participated in this retrospective study.

\section{Compliance with ethical standards}

Conflict of interest The authors have no conflicts of interest to disclose.

Human rights statement and informed consent The requirement for the investigator to obtain a signed consent form from each patient was waived given the anonymous nature of the data employed. Our protocol was approved by the ethics committee of the Faculty of Medicine at the University of Tokyo.

\section{References}

1. Brown LM, Devesa SS, Chow WH. Incidence of adenocarcinoma of the esophagus among white Americans by sex, stage, and age. J Natl Cancer Inst. 2008;100:1184-7.

2. Dikken JL, Lemmens VE, Wouters MW, Wijnhoven BP, Siersema PD, Nieuwenhuijzen GA, et al. Increased incidence and survival for oesophageal cancer but not for gastric cardia cancer in the Netherlands. Eur J Cancer. 2012;48:1624-32.

3. Miyazaki T, Inose T, Tanaka N, Yokobori T, Suzuki S, Ozawa D, et al. Management of Barrett's esophageal carcinoma. Surg Today. 2013;43:353-60.

4. Ferro A, Peleteiro B, Malvezzi M, Bosetti C, Bertuccio P, Levi F, et al. Worldwide trends in gastric cancer mortality (1980-2011), 
with predictions to 2015, and incidence by subtype. Eur J Cancer. 2014;50:1330-44.

5. Kusano C, Gotoda T, Khor CJ, Katai H, Kato H, Taniguchi H, et al. Changing trends in the proportion of adenocarcinoma of the esophagogastric junction in a large tertiary referral center in Japan. J Gastroenterol Hepatol. 2008;23:1662-5.

6. Mariette C, Piessen G, Briez N, Gronnier C, Triboulet JP. Oesophagogastric junction adenocarcinoma: which therapeutic approach? Lancet Oncol. 2011;12:296-305.

7. Japanese classification of gastric carcinoma: 3rd English edition. Gastric Cancer. 2011;14:101-112.

8. Ajani JA, Barthel JS, Bentrem DJ, D’Amico TA, Das P, Denlinger CS, et al. Esophageal and esophagogastric junction cancers. J Natl Compr Canc Netw. 2011;9:830-87.

9. Society JE. Japanese classification of esophageal cancer, 2nd English edition. Tokyo, Kanehara.

10. Sobin LH, Gospodarowicz MK, Wittekind CH. TNM Classification of Malignant TumoursWiley-Blackwell.

11. Sasako M, McCulloch P, Kinoshita T, Maruyama K. New method to evaluate the therapeutic value of lymph node dissection for gastric cancer. Br J Surg. 1995;82:346-51.

12. Ozawa $\mathrm{S}$, Tachimori $\mathrm{Y}$, Baba $\mathrm{H}$, Matsubara $\mathrm{H}$, Muro K, Numasaki H, et al. Comprehensive Registry of Esophageal Cancer in Japan, 2001. Esophagus. 2009;6:95-110.

13. Tachimori Y, Ozawa S, Fujishiro M, Matsubara H, Numasaki H, Oyama T, et al. Comprehensive Registry of Esophageal Cancer in Japan, 2005. Esophagus. 2014;11:1-20.

14. Tachimori Y, Ozawa S, Numasaki H, Fujishiro M, Matsubara H, Oyama T, et al. Comprehensive Registry of Esophageal Cancer in Japan, 2009. Esophagus. 2016;13:110-37.

15. Yabusaki H, Nashimoto A, Matsuki A, Aizawa M. Comparison of the surgical treatment strategies for Siewert type II squamous cell carcinoma in the same area as esophagogastric junction carcinoma: data from a single Japanese high-volume cancer center. Surg Today. 2014;44:1522-8.

16. Yamashita H, Katai H, Morita S, Saka M, Taniguchi H, Fukagawa T. Optimal extent of lymph node dissection for Siewert type II esophagogastric junction carcinoma. Ann Surg. 2011;254:274-80.

17. Hosokawa Y, Kinoshita T, Konishi M, Takahashi S, Gotohda N, Kato Y, et al. Clinicopathological features and prognostic factors of adenocarcinoma of the esophagogastric junction according to Siewert classification: experiences at a single institution in Japan. Ann Surg Oncol. 2012;19:677-83.

18. Mine S, Sano T, Hiki N, Yamada K, Nunobe S, Yamaguchi T. Lymphadenectomy around the left renal vein in Siewert type II adenocarcinoma of the oesophagogastric junction. Br J Surg. 2013;100:261-6.
19. Yoshikawa T, Takeuchi H, Hasegawa S, Nozaki I, Kishi K, Ito S, et al. Theoretical therapeutic impact of lymph node dissection on adenocarcinoma and squamous cell carcinoma of the esophagogastric junction. Gastric Cancer. 2016;19:143-9.

20. Siewert JR, Feith M, Werner M, Stein HJ. Adenocarcinoma of the esophagogastric junction: results of surgical therapy based on anatomical/topographic classification in 1,002 consecutive patients. Ann Surg. 2000;232:353-61.

21. Johansson J, Djerf P, Oberg S, Zilling T, von Holstein CS, Johnsson F, et al. Two different surgical approaches in the treatment of adenocarcinoma at the gastroesophageal junction. World J Surg. 2008;32:1013-20.

22. Takeuchi H, Fujii H, Ando N, Ozawa S, Saikawa Y, Suda K, et al. Validation study of radio-guided sentinel lymph node navigation in esophageal cancer. Ann Surg. 2009;249:757-63.

23. Sano T, Sasako M, Mizusawa J, Yamamoto S, Katai H, Yoshikawa $\mathrm{T}$, et al. Randomized Controlled Trial to Evaluate Splenectomy in Total Gastrectomy for Proximal Gastric Carcinoma. Ann Surg. 2016.

24. Peyre CG, Hagen JA, DeMeester SR, Van Lanschot JJ, Holscher A, Law S, et al. Predicting systemic disease in patients with esophageal cancer after esophagectomy: a multinational study on the significance of the number of involved lymph nodes. Ann Surg. 2008;248:979-85.

25. van Hagen P, Hulshof MC, van Lanschot JJ, Steyerberg EW, van Berge Henegouwen MI, Wijnhoven BP, et al. Preoperative chemoradiotherapy for esophageal or junctional cancer. N Engl J Med. 2012;366:2074-84.

26. Fujitani K, Miyashiro I, Mikata S, Tamura S, Imamura H, Hara J, et al. Pattern of abdominal nodal spread and optimal abdominal lymphadenectomy for advanced Siewert type II adenocarcinoma of the cardia: results of a multicenter study. Gastric Cancer. $2013 ; 16: 301-8$.

27. Matsuda T, Kurokawa Y, Yoshikawa T, Kishi K, Misawa K, Ohi $\mathrm{M}$, et al. Clinicopathological characteristics and prognostic factors of patients with siewert type II esophagogastric junction carcinoma: a retrospective multicenter study. World J Surg. 2016;40:1672-9.

28. Aikou T, Shimazu H. Difference in main lymphatic pathways from the lower esophagus and gastric cardia. Jpn J Surg. 1989;19:290-5.

29. Rice TW, Zuccaro G Jr, Adelstein DJ, Rybicki LA, Blackstone EH, Goldblum JR. Esophageal carcinoma: depth of tumor invasion is predictive of regional lymph node status. Ann Thorac Surg. 1998;65:787-92.

30. Japanese Gastric Cancer Association. Japanese gastric cancer treatment guidelines 2014 (ver. 4). Gastric Cancer, Epub ahead of print. 